\section{Beevor's Sign in Myotonic Dystrophy Type 1: Do we need to check in every neuromuscular patient?}

\author{
Davood Fathi ${ }^{1,2}$ MD, PhD; Shahriar Nafissi² MD
}

\author{
${ }^{1}$ Brain and Spinal Cord Injury Research Center, \\ Neuroscience Institute, Tehran University of Medical \\ Sciences, Tehran, Iran \\ ${ }^{2}$ Neurology Department, Shariati Hospital, Tehran \\ University of Medical Sciences, Tehran, Iran
}

Keywords: Beevor's sign, Myotonic dystrophy type l, facioscapulohumeral dystrophy

\section{Introduction}

Beevor's sign, named after British neurologist Charles Edward Beevor (1854-1908), is characterized by upward deviation of the umbilicus upon attempted sitting from supine position, as a result of weakness of the rectus abdominis muscles (1-3). While commonly attributed to patients with spinal cord or root lesions between T10 and T12, in the first description of this finding, Dr Beevor also mentioned two cases in which the umbilicus deviated downwards due to weakness of the upper rectus abdominis muscles in the setting of an underlying myopathy in one of them (2). There are studies which have mentioned the association of Beevor's sign and facioscapulohumeral dystrophy (FSHD) with a sensitivity of $95 \%$ and specificity of $97 \%$ (4-6). In addition to FSHD and spinal cord and root lesions (7), several other disorders have been reported to be associated with Beevor's sign including myotonic dystrophy type 1 (5), late-onset Pompe's disease (5,8), GNE myopathy (9), sporadic inclusion body myositis (10), tubular aggregate myopathy (4), and amyotrophic lateral sclerosis $(3,11)$. Here, we report a patient with myotonic dystrophy type 1 who showed a positive Beevor's sign when examined thoroughly.

\section{Case Report}

A 30-year-old man presented with a 10-year history of difficulty in extending his fingers when trying to open a bottle cap. He noticed progressive weakness in the upper extremities followed which progressed to involve the lower limbs as well. He denied any respiratory, bulbar, or ocular complaints. No consanguinity was noted on family history. Past medical history was negative for any systemic disorders. He was not on any medications.
The patient's neurological examination revealed normal mental status. Cranial nerve examination was notable for bifacial weakness, bi-temporal wasting and atrophy, and neck flexor muscles weakness, graded $4 / 5$. There was no winging of the scapula. Manual muscle examination showed bilateral $5^{-/ 5}$ weakness of deltoid, biceps, and triceps, wrist extension weakness of $4 / 5$, First dorsal interosseous weakness of $5^{-/ 5}$, and flexor pollicis longus weakness of $4^{-} / 5$. In the lower limbs, iliopsoas force was normal but bilateral quadriceps, tibialis anterior, and plantar flexion were weak with grades of $4 / 5,3 / 5$, and $4 / 5$, respectively. There was percussion myotonia in extensor digitorum communis and abductor pollicis brevis muscles. Axial muscle examination showed a typical Beevor's sign (Figure 1).
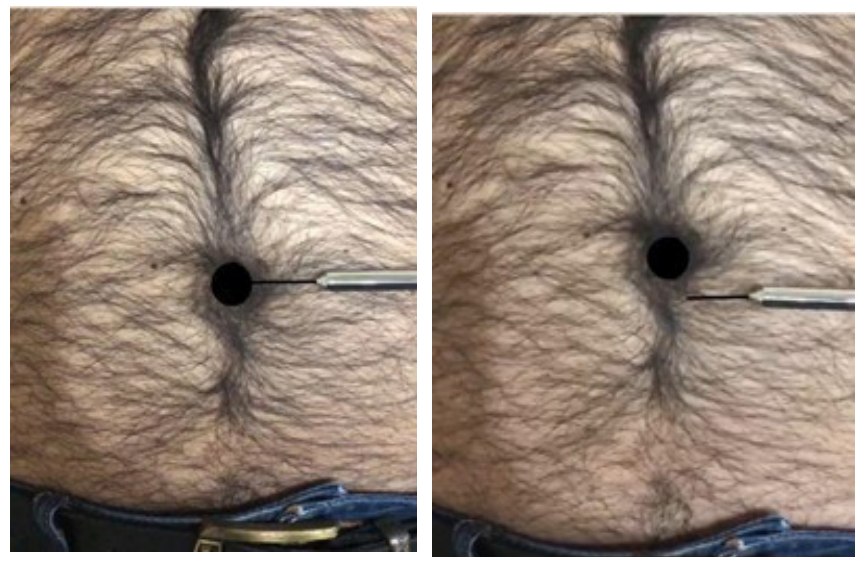

Figure 1. Part A (left): the patient is in the supine position with the handle of reflex hammer at the level of the umbilicus. Part B (right): the patient is asked to try to sit up with arms flexed and crossed over the chest and the umbilicus has moved upward from the fixed level of the handle of the reflex hammer (positive Beevor's sign).

Given the above constellation of signs and symptoms, electromyography was performed. We noted typical myotonic discharges in the first dorsal interosseous, biceps, tibialis anterior, and medial gastrocnemius muscles. The patient also underwent cardiology consultation with echocardiography. He was noted to have a normal ejection fraction without any structural or electrophysiologic abnormalities. Genetic testing was ordered to evaluate for CTG trinucleotide repeat expansion study in the DMPK gene. This test revealed pathologic CTG repeat expansion, confirming a diagnosis of myotonic dystrophy type 1 . The patient has signed a consent for this case report.

\section{Discussion}

Beevor's sign, after being initially observed in patients with spinal cord lesions, has been since reported in different neuromuscular disorders (table 1). Among all myopathies, 
FSHD is most commonly associated with Beevor's sign. Although in two studies, Beevor's sign has been reported with high sensitivity for FSHD (4) (6), in another study with both typical and atypical phenotypes of genetically proven FSHD patients despite the high specificity of $97 \%$, the overall sensitivity in combined group of typical and atypical FSHD patients for this sign was 54\% which could be explained by a significant numbers of the atypical cases of FSHD in this study (5). The sensitivity for typical cases was $85 \%$ and for atypical group was $27 \%$ (5). In addition, investigating Beevor's sign in a wide range of 65 neuromuscular patients with myopathies other than FSHD revealed that only 2 ( 1 with myotonic dystrophy type 1 and 1 with Pompe's disease) showed positive Beevor's sign, however only 2 patients with myotonic dystrophy type 1 and 2 patients with Pompe's disease were included in the cohort (5).

In another study with 17 genetically confirmed cases of GNE myopathy, the investigators reported positive Beevor's sign in 15 cases $(88.2 \%)$ proposing this sign as a clinical indicator for GNE myopathy (9). Although the researchers did not observe Beevor's sign in 10 Miyoshi myopathy and 5 myotonic dystrophy patients, the type of myotonic dystrophy was not specified (9). Sporadic inclusion body myositis also has been reported to be associated with positive Beevor's sign after developing abdominal wall muscle weakness and abdominal protrusion (10). Looking at our case of positive Beevor's sign in a patient with myotonic dystrophy type 1 in addition to the presence of this sign in a wide range of neuromuscular disorders persuades us to propose the investigation of Beevor's sign as part of the routine neuromuscular examination. Looking for this old clinical sign in patients with a broader spectrum of neuromuscular disorders may help clarify the true sensitivity and specificity of Beevor's sign for distinct diagnosis.

\section{Corresponding Author}

Davood Fathi, MD, PhD

Email address: dr.davoodfathi@gmail.com

\section{References}

1. McCarter SJ, Burkholder DB, Klaas JP, Boes CJ. Charles E. Beevor's lasting contributions to neurology. Neurology. 2018;90(11):513-7. DOI: $10.1212 /$ WNL.0000000000005127

2. Tashiro K. Charles Edward Beevor (1854-1908). J Neurol. 2001;248(7):635-6. DOI: 10.1007/s004150170149

3. Pearce JM. Beevor's sign [Internet]. Vol. 53, European neurology. 2005. p. 208-9. Available from: http:// dx.doi.org/10.1159/000086731

4. Shahrizaila N, Wills AJ. Significance of Beevor's sign in facioscapulohumeral dystrophy and other neuromuscular diseases. J Neurol Neurosurg Psychiatry. 2005;76(6):869-70. DOI: 10.1136/jnnp.2004.052019

5. Eger K, Jordan B, Habermann S, Zierz S. Beevor's sign in facioscapulohumeral muscular dystrophy: an old sign with new implications [Internet]. Vol. 257, Journal of

Table 1. Summary of studies investigating Beevor's sign in different neuromuscular disorders

\begin{tabular}{|c|c|c|}
\hline Author-year & $\begin{array}{l}\text { The disorders which investigated for } \\
\text { Beevor's sign }\end{array}$ & Beevor's sign positivity \\
\hline Awerbuch et al - 1990 (6) & $\begin{array}{l}30 \text { FSHD patients and } 40 \text { other } \\
\text { neuromuscular disorders }\end{array}$ & $\begin{array}{l}\text { In } 27 / 30 \text { FSHD but } 0 / 40 \text { of the other } \\
\text { neuromuscular disorders }\end{array}$ \\
\hline Shahrizaila et al - 2005 (4) & $\begin{array}{l}20 \text { FSHD, } 28 \text { with other neuromuscular } \\
\text { disorders, and } 20 \text { neurological patients } \\
\text { without muscle disease }\end{array}$ & $\begin{array}{l}\text { In } 19 / 20 \text { FSHD, in } 2 / 28 \text { with other } \\
\text { neuromuscular disorders, and } 0 / 20 \text { with } \\
\text { neurological controls }\end{array}$ \\
\hline Leon-Sarmiento et al - 2007 (7) & $\begin{array}{l}\text { A case of spinal cord infarction presenting } \\
\text { with Beevor's sign }\end{array}$ & NA \\
\hline Eger et al - 2010 (5) & $\begin{array}{l}28 \text { patients with FSHD and } 65 \text { patients } \\
\text { with other neuromuscular diseases }\end{array}$ & $\begin{array}{l}\text { In } 15 / 28 \text { FSHD patients but } 2 / 65 \text { in other } \\
\text { neuromuscular patients. }\end{array}$ \\
\hline Sugie et al - 2015 (10) & $\begin{array}{l}\text { A case of sporadic inclusion body myositis } \\
\text { presenting with Beevor's sign }\end{array}$ & NA \\
\hline Matteo Garibaldi et al - 2016 (8) & $\begin{array}{l}\text { A case of late onset Pompe disease } \\
\text { presenting with Beevor's sign }\end{array}$ & NA \\
\hline Preethish-Kumar et al - 2016 (9) & 17 GNE myopathy patients & In 15/17 GNE patients \\
\hline
\end{tabular}

NA: not applicable 
Neurology. 2010. p. 436-8. Available from: http://dx.doi. org/10.1007/s00415-009-5342-9

6. Awerbuch GI, Nigro MA, Wishnow R. Beevor's Sign and Facioscapulohumeral Dystrophy. Arch Neurol. 1990;47(11):1208-9. doi: 10.1001/ archneur.1990.00530110066018.

7. Leon-Sarmiento FE, Bayona EA, Bayona-Prieto J. A sudden beevor's sign. Clinical Medicine and Research. 2007;5(2):121-2. DOI: $10.3121 / \mathrm{cmr} .2007 .746$

8. Garibaldi M, Diaz-Manera J, Gallardo E, Antonini G. Teaching Video Neuro Images: The Beevor sign in lateonset Pompe disease. Neurology. 2016;86(24):e250-1. DOI: 10.1212/WNL.0000000000002772

9. Preethish-Kumar V, Pogoryelova O, Polavarapu K, Gayathri N, Seena V, Hudson J, et al. Beevor's sign: a potential clinical marker for GNE myopathy. Eur J Neurol. 2016;23(8):e46-8. DOI: 10.1111/ene.13041

10. Sugie K, Kumazawa A, Ueno S. Sporadic inclusion body myositis presenting with beevor's sign. Intern Med. 2015;54(21):2793-4. doi: 10.2169/ internalmedicine.54.5002.

11. Desai JD. Beevor's sign. Ann Indian Acad Neurol. 2012;15(2):94-5. 